\title{
A Study of the Grading of English Language Scripts of Technical University Students in Ghana
}

\author{
Edward Owusu ${ }^{1}$ \\ ${ }^{1}$ Sunyani Technical University, Ghana \\ Correspondence: Edward Owusu, Department of Communication Studies, and Directorate of Quality Assurance \\ and Academic Planning, Sunyani Technical University, Sunyani, Ghana. Tel: 233-0352-025-514.
}

Received: January 8, 2021; Accepted: Februry 28, 2021; Published: March 8, 2021

The research is financed by the researcher.

\begin{abstract}
This paper assesses how English language texts of Technical University (TU) students in Ghana are graded. In their quest for their certificates, Higher National Diploma (HND) students are required to write Communication Skills I and II papers in the first year. Nonetheless, most HND students do not normally perform well in these two courses. The objectives of the paper were, therefore, to find out the type of errors TU students make; and the influence that Direct Corrective Feedback (DCF) has on their texts. The paper was grounded in Noticing Hypothesis theoretical framework. The design of the research was sequential exploratory mixed method (Note 1). The participants for the study were selected from four technical universities - Ho, Koforidua, Kumasi, and Sunyani Technical Universities. From each of the technical universities, 20 participants were randomly selected. Therefore, the sample size, in terms of the participants, was 80 . However, 240 raw data were collected. That is each of the 80 participants composed one letter at the pre-test stage. After grading their scripts with DCF technique, the participants were, again, asked to compose another letter at the post-test stage. Also, the participants were made to fill questionnaire item each. SPSS and BLAF were used in analyzing the questionnaire items and the scripts respectively (Note 2). The findings of the study showed that DCF treats written errors effectively. The study, therefore, recommends that assessments of letter-based tasks of TU students should be made up of both pre- and post-test items, and DCF should be used in assessing HND students' letter or essay-based scripts.
\end{abstract}

Keywords: errors, pre-test, post-test, direct corrective feedback, indirect corrective feedback, English language

\section{Introduction}

English Language Teaching (ELT) continues to be more dynamic and complex today than it has been in the past (Renandya \& Widodo, 2016, p.3). One of the factors which contributes to the dynamism and complexity of English language is the fact that English has borrowed from most of the languages of the world extensively. Because of the complex nature of English language, most Second Language Learners (SLL) and teachers, encounter several challenges in its learning and teaching. In Ghana, Technical University (TU) students are one of the groups of SLLs that usually encounter some challenges of English language teaching and learning. In their pursuit of Higher National Diploma (HND) in various fields, TU students are expected to register two English language-based courses in the first year. Communication Skills I and II are the English language-based courses that all HND students are required to undertake in the first year. However, most TU students do not usually perform creditably in these two courses. Apart from the fact that most of these students usually enroll on the HND programme with poor English language results, most stakeholders also blame students' poor performance in Communication Skills on the corrective feedback or marking style of the TU language teacher. Therefore, the objectives of this current paper were to find out the type of errors that TU students commit; and the influence that Direct Corrective Feedback (DCF) has on their texts. The research questions were:

what type of errors do TU students make?

what influence does DCF have on students' texts?

This study has a lot of significance for stakeholders of second language teaching and learning. For language teachers, the study provides a framework about how grading of TU students should be done. The knowledge gained from this current study would facilitate the language teacher's selection of tools and interventions for language 
teaching and grading. Since second language learners (SLL) commit several errors in their written communication, this study gives a fair idea about some of the errors that SLL commit. Again, policy makers, regulators of education, and parents can all benefit from the findings of the study by understanding the role that DCF plays in the grading of the texts of SLL. Also, in terms of grading, the study is a contribution to the debate on corrective feedback as it showcases an analytical framework for grading of business letters (BLAF).

\section{Literature Review}

\subsection{CF Debate}

Corrective feedback (CF) is one of the emerging debates in Second Language Teaching and Learning (SLTL). The debate started when Truscott (1996) argued that grammar correction in second language (L2) writing should be abandoned. According to Truscott $(1996,1999)$ grammar correction has harmful effects of ineffectuality, empirical evidence of failure, and detrimental consequences on the L2 student. However, Ferris (1999), drew on a number of works in favour of CF (i.e. Bates et al., 1993; Ferris, 1995c; Ellis, 1998) and refuted the claims of Truscott (1996) by making a strong argument about the efficacy of grammar correction as: CF helps students to develop their language skills, it improves students' accuracy in writing, it is too important to be ruled out, and it facilitates teachers' ability to respond attentively and effectively to students' needs (Note 3).

Since the publication of Truscott (1996) and the subsequent rebuttal of Ferris (1996), there has been a huge debate in grammar correction. For example, in Chandler (2003), Mubarak (2013), Owusu (2017, 2019, 2020b) Direct Corrective Feedback (DCF) was strong in correcting errors as against Indirect Corrective Feedback (ICF), and No Corrective Feedback (NCF) techniques. Also, Bitchener et al., (2005), argued that L2 teachers should provide their learners with both oral and written CF on errors. Beuningen, (2010) also argued that written CF can foster SLA, and subsequently lead to accuracy development. Ellis (2009) provided ten guidelines for providing CF on students' errors. In Junqueira and Payant (2015) it was realized that giving CF was fundamental for students' success in improving their writing skills. Conversely, some classical research works published earlier (e.g. Hendrickson, 1978; Semke, 1984; Robb et al., 1986; Leki, 1990; Kepner, 1991; Krashen, 1992; and Sheppard, 1992) have concluded that $\mathrm{CF}$ is ineffective.

\subsection{Corrective Feedback Defined}

Chaudron (1988, p.150) has indicated that the term CF incorporates different layers of meaning. In his opinion, the term "treatment of error" may simply refer to "any teacher behaviour following an error that minimally attempts to inform the learner of the fact of error". The treatment may not be evident to the student in terms of the response it elicits, or it may make a significant effort "to elicit a revised student response."

Nevertheless, Han (2008) as cited in Méndez et al., (2010, p.241) proposes that error correction implies an evident and direct correction, whereas $\mathrm{CF}$ is a generic way of providing some clues, or eliciting some correction, besides the direct correction made by the teacher. Han (2008) has thus, conceptualised the term error correction as an immediate and a palpable way of correcting errors and CF as a broad term of offering feedback on students' errors. Ellis, et al. (2006, p.340) define CF as:

... the form of responses to learner utterances that contain error. The responses can consist of (a) an indication that an error has been committed, (b) provision of the correct target language form, or (c) metalinguistic information about the nature of the error, or any combination of these.

CF can also be defined as teacher's response to students' written or verbal structures that seeks to critique the structures (Owusu, 2017, p. 32). With this definition, Owusu (2017) argues that CF is not always applied to students' faulty structures only. There are times the teacher may use a CF with the idea of encouraging the student for doing the right thing. This is where the teacher's commendation role comes in. The modification role is where the teacher uses a particular type of CF with the idea of drawing the student's attention to a faulty structure that needs to be changed.

\subsection{Direct and Indirect CF}

Corrective Feedback (CF) can be direct (explicit) or indirect (implicit) (Ferris, 2003; Lightbown \& Spada, 1999). Direct or explicit CF has to do with teacher's provision of the correct linguistic form or structure on the errors and mistakes found in the learner's script. This may comprise the crossing out of any unnecessary structure (for example: morpheme, word, phrase, clause, or sentence); the insertion of a missing structure; or writing the correct form or structure. The indirect or implicit CF is used when a teacher indicates that an error has been made without clearly mentioning the type of error or writing the correct form above the error found (Ferris 2003). The indirect CF may take the form of underlining or circling the error, recording in the margin of the script the number of errors made in a given line, or using a code to show where the error has been made and what type of error it is (Ferris \& 
Roberts 2001). Here, students are left to reread and subsequently edit the errors in their scripts rather than the teacher indicating it clearly. As stated earlier, several empirical studies (for example, Mubarak, 2013; Owusu, 2017; Owusu, 2019; Owusu, 2020) have revealed the efficacy of the DCF method. Consequently, these studies recommended DCF for teachers to use in their various SLA classrooms. So, the objectives of the paper were to find out the type of errors TU students make; and the influence that DCF has on their scripts.

\subsection{Empirical Review on $C F$}

Ever since Truscott (1996) published his paper, a lot of empirical studies have been conducted on corrective feedback. The empirical review of this current research looks at four studies that are related to the current study. These studies are Farrokhi and Sattarpour (2012), Mubarak (2013), Pakbaz (2014), and Junqueira and Payant (2015).

Farrokhi and Sattarpour (2012) studied the effects of direct written corrective feedback on improvement of grammatical accuracy of high-proficient L2 learners. The objectives were (1) to assess whether direct written CF can help high-proficient L2 learners improve in the accurate use of functions of English articles; and (2) to assess whether there are any differential effects in providing two direct written CFs of focused and unfocused. The review of literature was mainly centred on studies comparing different types of corrective feedback such as Semke (1984), Robb et al. (1986), Ferris and Robert (2001), Ferris (2003), Chandler (2003), and Bitchener et al. (2005). The participants were 60 high-proficient Iranian EFL learners; 26 of whom were male participants, with 34 being female participants. (Farrokhi and Sattarpour, 2012, p. 52). The study showed differences in the results of pre- and post-tests items (Farrokhi and Sattarpour, 2012, p. 53); which generally means that corrective feedback works as the participants in the experimental groups outperformed those in the control group. The study again emphasised that 'focused written CF is more effective than the unfocused written CF' (Farrokhi and Sattarpour, 2012, p. 54).

Mubarak (2013) conducted a study on "Corrective feedback in L2 writing: A study of practices and effectiveness in the Bahrain context." The study, which is a PhD dissertation, was submitted to the University of Sheffield. The objectives of the study were (1) to examine whether or not CF leads to increased accuracy and complexity of L2 students' writing at the University of Bahrain; (2) to investigate the effectiveness of direct and indirect written CFs; and (3) to investigate the beliefs of teachers and students on feedback through interviews and questionnaires (Mubarak, 2013, p.17) (Note 4). Forty-six (46) participants constituted the student-subjects. The findings of the quasi-experiment revealed that direct and indirect CFs have no substantial effect on accuracy and complexity (grammatical and lexical) of students' scripts, though they improved in the course of the experiment. The results of the interviews and questionnaires demonstrated the preference of students for direct feedback instead of the indirect one. Also, the study revealed the beliefs of students and teachers about CF. They valued CF and believed it was beneficial, though the results of the quasi-experimental proved otherwise. Classroom observations showed some challenges in the teaching and learning of L2 writing and also in CF methods used at the University of Bahrain in general. For example, it was observed that students were not allowed to submit a second draft of their composition after the first draft has been marked (Mubarak, 2013, p. 165). Mubarak (2013, p. 212-214) recommended that (1) errors should be corrected using the direct CF; (2), teachers should experiment with peer feedback; (3) teachers could use a variety of styles (for example, praise, criticism, and suggestion) to give their comments about students' oral and written discourse.

Pakbaz (2014) investigated the effect of written corrective feedback on EFL learners' writing performance, by using explicit and implicit techniques. The participants for the study were 20 intermediate learners of English language from Adib Language Institute, Iran (Pakbaz, 2014, p. 14). The thesis statement of the study was in spite of the large body of research, there seems to be no unified agreement on the effectiveness of written corrective feedback on L2 learners' written performance (Pakbaz, 2014, p. 12). The research questions for the study were: (1) Does giving written corrective feedback have any effect on the writing performance of Iranian EFL learners? (2) Is there any significant difference between giving implicit versus explicit written feedback on the writing performance of Iranian EFL learners? (3) Is there any significant difference between the use of past tense in three tasks of pre-test, immediate post-test and the delayed post-test? (4) Is there any significant difference between the use of definite/indefinite articles in three tasks of pre-test, immediate post-test and the delayed post-test? (Pakbaz, 2014, p. 14). The instrument used was a Standardized Placement Test in English designed by Allan (1992).The results of the study revealed that there was no difference between the two groups (implicit and explicit) on their correct use of the specified structures. Learners thus found their own way of responding to errors irrespective of the feedback style (that is whether implicit or explicit) the teacher used. This finding is in consonance with Semke (1984). Pakbaz (2014) is a contribution to research in terms of implicit and explicit feedback techniques. In terms of the instruments used, the study is detailed. The participants responded to three essay-based questions in addition to answering questions on a Standardized Placement Test in three styles of pre-test, immediate post-test, and 
delayed post-test. However, we are not told of the total population of the case, and Pakbaz's (2014) bases for selecting only 20 respondents for this longitudinal study.

Junqueira and Payant (2015) investigated teacher feedback views and procedures of an L2 writing teacher for a period of one semester. The main participant was an MA TESOL student-teacher who taught English to ESL students at the university level. The sources of data were four sets of commented-on students' essays, a reflective journal, two structured interviews, and member checking with the teacher. Four forms of written corrective feedback were used on the students' coded essays. These were: direct, direct with explanation, indirect, and indirect with explanation. The CFs used on the essays were compared to Kim's beliefs, as discussed in her journals and interviews. The findings of the study showed that Kim had an intricate set of beliefs in terms of what should be addressed and how it should be carried out. The study also revealed that although CF was time-consuming and 'intimidating' task, Kim supported the idea that giving CF was fundamental for students' success in improving their writing skills.

\subsection{Theoretical Framework}

The theoretical framework that underpins the paper is Noticing Hypothesis $(\mathrm{NH})$. This theory which was advocated by Schmidt (1990; 1993a), holds that second language learners must consciously notice the grammatical form of their input in order to acquire grammar (Schmidt, 1990, 2001, 2010; Truscott, 1998). Thus, input does not become intake for language learning unless it is noticed, that is, intentionally registered (Schmidt, 2010, p.1). This means that for one to obtain grammatical knowledge, one has to deliberately detect the grammatical structure of one's input. The NH has strong and the weak forms. Supported by Schmidt (1990, 1993a, 1994, 1995b), the strong form states that 'noticing is a necessary condition for learning.' For a learner to study any learning material, the principle of noticing is instrumental. For example, if someone wants to read a material written in a target language, he or she must first identify the grammatical form of his or her input before he or she can obtain the grammar of the language. The weak form simply says that 'noticing is helpful but might not be necessary' (Truscott, 1998, p. 104). Though the weak form recognizes the potency of the hypothesis, it does not see it as an indispensable tool that must happen before learning will take place. $\mathrm{CF}$ which is hinged on the strong form of $\mathrm{NH}$ is one approach that can be employed to help establish the grammatical flaws that SLLs commit.

\section{Method}

\subsection{Research Design}

The design of the study was Sequential Exploratory Mixed Methods (SEMM). Multiple case studies and experimental design were the specific approaches used. SEMM involves the process of first, collecting qualitative data to explain a situation, and then soliciting quantitative data with the view of providing explanations to the relationships established in the qualitative data (Creswell et al., 2003, p.211). The aim of such design is to explore a phenomenon. So, I first collected classroom data in the form of texts at both pre- and post-test levels. After that, I used questionnaire items to collect raw data.

\subsection{Participants, Sample, Sample Size, and Sampling Techniques}

The participants for the study were drawn from 80 level 100 students of Ho, Koforidua, Kumasi, and Sunyani Technical Universities. These students were pursuing various programmes in the 2016/2017 Academic Year. From each of the 4 selected technical universities, 20 participants were randomly selected. First, the participants were stratified into different strata of programme of study, before they were randomly selected. Therefore, the sample size in terms of the participants was 80 . However, in terms of data, 240 raw data were collected. That is, each of the 80 participants composed one letter at the pre-test stage. After grading their scripts with DCF technique, the participants were again asked to compose another letter at the post-test stage. When all the 80 participants completed the pre- and post-test stages, they were made to fill a questionnaire item each.

\subsection{Data Collection Instruments, Procedure, and Analysis}

The two instruments used in collecting raw data from the field were classroom scripts and questionnaire items. At the pre-test level, the selected participants were asked to write a business letter (Note 5). After grading their scripts with DCF technique, the participants were again, asked to write another letter at the post-test stage. When all the 80 participants completed the pre- and post-test stages, they were made to fill a questionnaire item each. SPSS (Version 16) and BLAF (please refer to Figure 1) were used in analyzing the questionnaire items and the scripts respectively. 


\subsubsection{Business Letter Analytical Framework (BLAF)}

Propounded by Owusu (2017), Business Letter Analytical Framework (BLAF) has four independent variables of layout, rubrics, language and formatting, and grading. The layout has to do with how contents of the essay have been arranged. The framework suggests that grading of business letters should be done in an orderly manner. Any examiner who desires to use the framework should first look at the consistency (in any of the three layouts of blocked, modified, and simplified) used. After this, the examiner should look at the rubrics of the business letter. The rubrics are the use of a letterhead or senders address, reference number, recipient address, the date, salutation, title/heading, the body, subscription, signature, full name, and copy notation. In scrutinizing the rubrics, it is vital to check for the alignment of salutation and complimentary close (McClave, 2008, p. 132). The dependent variables generated from language and formatting are mechanics, grammar, and punctuation marks. Mechanics discusses issues of spelling, word-division, capitalization, and paragraph style. Grammar focuses on syntactic, concord, tense, semantic, and lexical errors. The framework further suggests that the grading of letters should be done by examining the content, expression, organisation, and mechanical accuracy. The content looks at whether the topic in question has been well-developed. The expression assesses adequacy of ideas developed in the various paragraphs. Organisation focuses on consistency of styles used; and mechanical accuracy focuses on grammar, and punctuation errors.

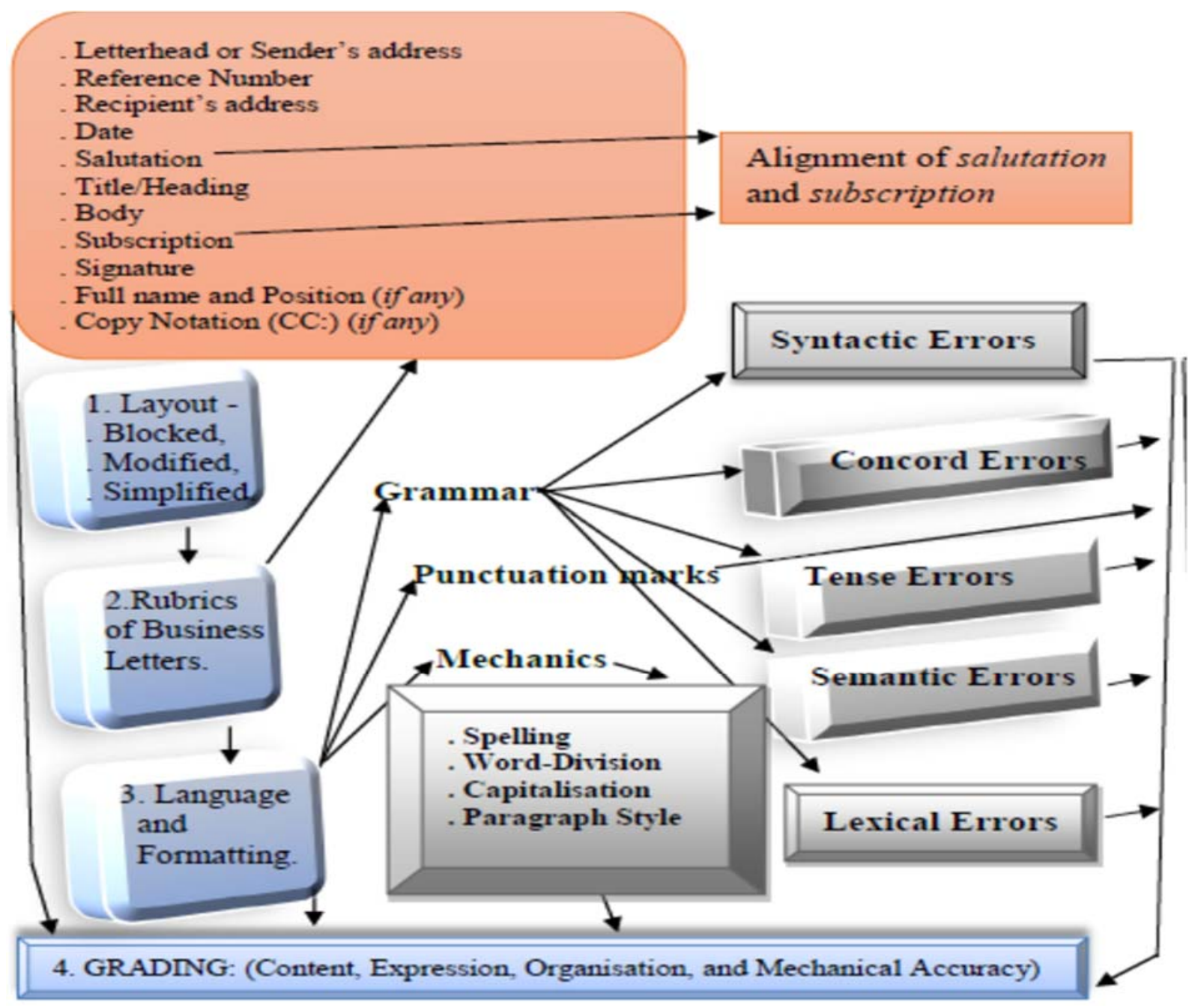

Figure 1. Business Letter Analytical Framework (BLAF) Owusu $(2017,117)$

\section{Results and Findings}

This section of the paper discusses the results and findings of the field data I collected with classroom texts and questionnaire items. For easy identification and anonymity, the classroom texts of the various participants were coded. The manual coding took into consideration the name of the participant's university, the serial number of 
the participant and the test type (pre/post-tests). While all pre-tests were coded A, post-tests were coded B. For example, the symbols of texts with code numbers KsA3 and SB2 will have this interpretation respectively: Ks (KsTU), A (pre-test), 3 (serial number of KsTU participant), S (STU), B (post-test), and 2 (serial number of STU participant). The findings are based on the objectives of the paper: the influence that DCF has on TU students' scripts, and the type of errors that TU students make.

4.1 The Influence of DCF on TU Students' Scripts

The study revealed that Direct Corrective Feedback (DCF) has positive influence on students' letters (scripts):

Table 1. Pre- and Post-Test Scores of HTU and KTU Participants

\begin{tabular}{|c|c|c|c|c|c|c|c|c|}
\hline \multicolumn{4}{|c|}{ RESULTS FROM HTU } & \multicolumn{5}{|c|}{ RESULTS FROM KTU } \\
\hline Code & $\begin{array}{l}\text { Pre-Test } \\
\text { Score }\end{array}$ & $\begin{array}{l}\text { Post-Test } \\
\text { Score }\end{array}$ & Comment & Code & $\begin{array}{l}\text { Pre-Test } \\
\text { Score }\end{array}$ & $\begin{array}{l}\text { Post- } \\
\text { Score }\end{array}$ & Test & Comment \\
\hline HA1 & 11 & & Score & KA1 & 11 & & & Score \\
\hline HB1 & & 12 & appreciated & KB1 & & 11 & & maintained \\
\hline HA2 & 9 & & Score & KA2 & 12 & & & Score \\
\hline HB2 & & 12 & appreciated & KB2 & & 13 & & appreciated \\
\hline HA3 & 12 & & Score & LA3 & 10 & & & Score \\
\hline HB3 & & 14 & appreciated & KB3 & & 11 & & appreciated \\
\hline HA4 & 10 & & Score & KA4 & 11 & & & Score \\
\hline HB4 & & 11 & appreciated & KB4 & & 12 & & appreciated \\
\hline HA5 & 9 & & Score & KA5 & 11 & & & Score \\
\hline HB5 & & 11 & appreciated & KB5 & & 13 & & appreciated \\
\hline HA6 & 12 & & Score & KA6 & 12 & & & Score \\
\hline HB6 & & 13 & appreciated & KB6 & & 14 & & appreciated \\
\hline HA7 & 9 & & Score & KA7 & 10 & & & Score \\
\hline HB7 & & 12 & appreciated & KB7 & & 12 & & appreciated \\
\hline HA8 & 13 & & Score & KA8 & 13 & & & Score \\
\hline HB8 & & 14 & appreciated & KB8 & & 15 & & appreciated \\
\hline HА9 & 7 & & Score & KA9 & 9 & & & Score \\
\hline HB9 & & 10 & appreciated & KB9 & & 11 & & appreciated \\
\hline HA10 & 6 & & Score & KA10 & 9 & & & Score \\
\hline HB10 & & 10 & appreciated & KB10 & & 11 & & appreciated \\
\hline HA11 & 10 & & Score & KA11 & 9 & & & Score \\
\hline HB11 & & 10 & maintained & KB11 & & 11 & & appreciated \\
\hline HA12 & 12 & & Score & KA12 & 10 & & & Score \\
\hline HB12 & & 13 & appreciated & KB12 & & 12 & & appreciated \\
\hline HA13 & 11 & & Score & KA13 & 9 & & & Score \\
\hline HB13 & & 12 & appreciated & KB13 & & 10 & & appreciated \\
\hline HA14 & 14 & & Score & KA14 & 12 & & & Score \\
\hline HB14 & & 15 & appreciated & KB14 & & 14 & & appreciated \\
\hline HA15 & 9 & & Score & KA15 & 10 & & & Score \\
\hline HB15 & & 10 & appreciated & KB15 & & 11 & & depreciated \\
\hline HA16 & 9 & & Score & KA16 & 12 & & & Score \\
\hline HB16 & & 12 & appreciated & KB16 & & 12 & & maintained \\
\hline HA17 & 10 & & Score & KA17 & 10 & & & Score \\
\hline HB17 & & 13 & appreciated & KB17 & & 11 & & appreciated \\
\hline HA18 & 12 & & Score & KA18 & 11 & & & Score \\
\hline HB18 & & 13 & appreciated & KB18 & & 12 & & Appreciated \\
\hline HA19 & 12 & & Score & KA19 & 9 & & & Score \\
\hline HB19 & & 7 & depreciated & KB19 & & 11 & & appreciated \\
\hline HA20 & 11 & & Score & KA20 & 12 & & & Score \\
\hline HB20 & & 13 & appreciated & KB20 & & 13 & & appreciated \\
\hline
\end{tabular}


From Table 1, the HTU participant with pre- and post-test codes of HA11 and HB11 had the same pre- and posttest results of 10 over 20 marks. But, the participant with pre- and post-test codes of HA19 and HB19 correspondingly, had a depreciation of results from 12 to 7 marks. With the exception of these two individuals, the rest of the 18 participants had an appreciation in their post-test results. This represents $80 \%$. From KTU, apart from participants 1 and 16 who registered the same marks for their pre- and post-tests, the rest of the participants had an appreciation of post-test scores. This also represents $80 \%$. This is an indication that HTU and KTU participants were able to notice their pre-test errors which were pointed out to them using DCF technique.

Table 2. Pre- and Post-Test Scores of KsTU and STU Participants

\begin{tabular}{|c|c|c|c|c|c|c|c|}
\hline \multicolumn{4}{|c|}{ RESULTS FROM KSTU } & \multicolumn{4}{|c|}{ RESULTS FROM STU } \\
\hline Code & $\begin{array}{l}\text { Pre-Test } \\
\text { Score }\end{array}$ & $\begin{array}{l}\text { Post-Test } \\
\text { Score }\end{array}$ & Comments & Code & $\begin{array}{l}\text { Pre-Test } \\
\text { Score }\end{array}$ & $\begin{array}{l}\text { Post- } \\
\text { Test } \\
\text { Score }\end{array}$ & Comments \\
\hline KsA1 & 8 & & Score & SA1 & 10 & & Score appreciated \\
\hline KsB1 & & 10 & appreciated & SB1 & & 12 & score apprectatea \\
\hline KsA2 & 7 & & Score & SA2 & 10 & & Score appreciated \\
\hline KsB2 & & 9 & appreciated & SB2 & & 11 & score apprectatea \\
\hline KsA3 & 8 & & Score & SA3 & 9 & & Score annreciatod \\
\hline KsB3 & & 8 & maintained & SB3 & & 12 & score apprectace \\
\hline KsA4 & 13 & & Score & SA4 & 14 & & \\
\hline KsB4 & & 14 & appreciated & SB4 & & 15 & score apprectatea \\
\hline KsA5 & 7 & & Score & SA5 & 11 & & Score maintained \\
\hline KsB5 & & 10 & appreciated & SB5 & & 11 & 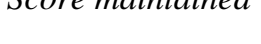 \\
\hline KsA6 & 12 & & Score & SA6 & 10 & & Score annreciated \\
\hline KsB6 & & 14 & appreciated & SB6 & & 12 & score apprectace \\
\hline KsA7 & 11 & & Score & SA7 & 10 & & Score anpreciated \\
\hline KsB7 & & 13 & appreciated & SB7 & & 13 & score apprectatea \\
\hline KsA8 & 7 & & Score & SA8 & 11 & & Score maintained \\
\hline KsB8 & & 9 & appreciated & SB8 & & 11 &  \\
\hline KsA9 & 10 & & Score & SA9 & 11 & & Score annreciated \\
\hline KsB9 & & 12 & appreciated & SB9 & & 13 & score apprectace \\
\hline KsA10 & 11 & & Score & SA10 & 10 & & Score annreciated \\
\hline KsB10 & & 12 & appreciated & SB10 & & 13 & score apprectatea \\
\hline KsA11 & 10 & & Score & SA11 & 11 & & Score annreciated \\
\hline KsB11 & & 12 & appreciated & SB11 & & 13 & score apprectatea \\
\hline KsA12 & 10 & & Score & SA12 & 11 & & Score annreciated \\
\hline KsB12 & & 12 & appreciated & SB12 & & 12 & score appreciated \\
\hline KsA13 & 8 & & Score & SA13 & 9 & & Score appreciated \\
\hline KsB13 & & 10 & appreciated & SB13 & & 10 & score apprectace \\
\hline KsA14 & 10 & & Score & SA14 & 11 & & Score annreciated \\
\hline KsB14 & & 12 & appreciated & SB14 & & 13 & score apprectatea \\
\hline KsA15 & 8 & & Score & SA15 & 14 & & d \\
\hline KsB15 & & 10 & appreciated & SB15 & & 15 & score apprectatea \\
\hline KsA16 & 13 & & Score & SA16 & 14 & & Conmennrogiatod \\
\hline KsB16 & & 14 & appreciated & SB16 & & 15 & score appreciatea \\
\hline KsA17 & 12 & & Score & SA17 & 15 & & Coere annrociatod \\
\hline KsB17 & & 14 & appreciated & SB17 & & 17 & score apprectatea \\
\hline KsA18 & 7 & & Score & SA18 & 12 & & Score \\
\hline KsB18 & & 9 & appreciated & SB18 & & 13 & Appreciated \\
\hline KsA19 & 11 & & Score & SA19 & 9 & & Score annreciated \\
\hline KsB19 & & 12 & appreciated & SB19 & & 13 & score apprectatea \\
\hline KsA20 & 14 & & Score & SA20 & 14 & & Score appreciated \\
\hline KsB20 & & 16 & appreciated & SB20 & & 15 & score apprectatea \\
\hline
\end{tabular}


From Table 2, participant 3 from KsTU registered 8 over 20 marks in both pre- and post-tests. Apart from participant 3, the other 19 participants (i.e. 90\%) performed better in the post-test. From STU two participants (5 and 8 ) had the same pre-and post-test marks of 11 over 20. Except for these two participants, the remaining 18 (i.e. $80 \%$ ) performed better in the post-tests conducted. This situation also shows the potency of DCF in correction of errors.

After the pre- and post-test assessments, the candidates were asked (using questionnaire items) whether the DCF technique of the assessor had a positive influence on their post-test results. Figure 2 shows the responses of the participants:

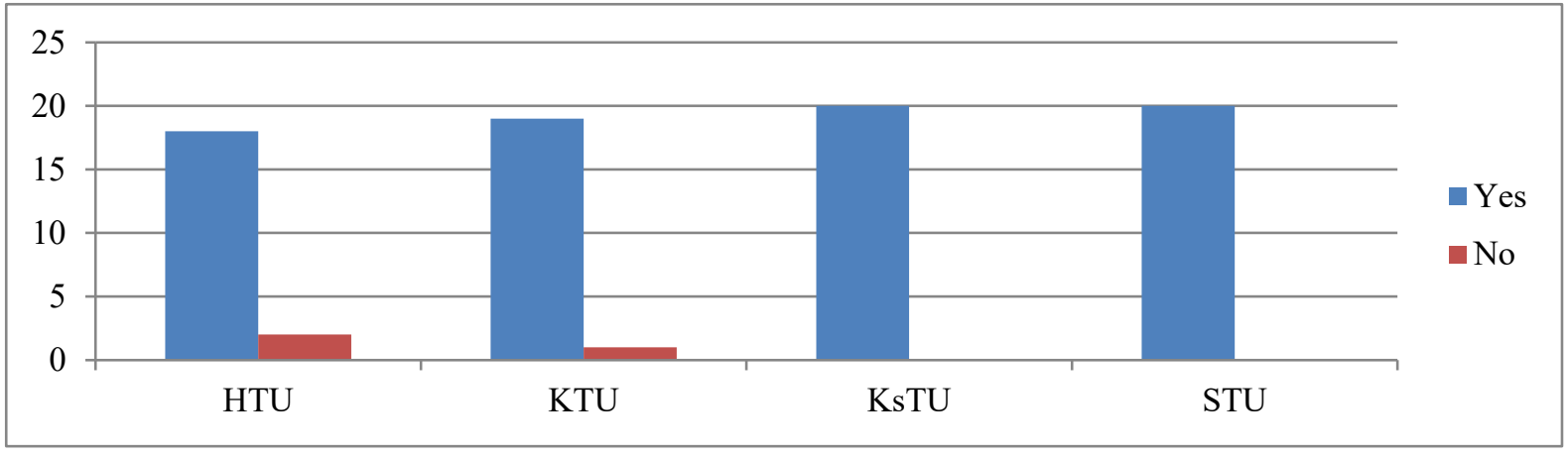

Figure 2. Response of Participants on the use of DCF

From Figure 2, one realizes that all the 20 participants (i.e. 100\%) from KsTU and STU responded positively that the DCF technique had a positive influence on their post-test scores. From HTU, apart from two participants, who responded negatively to the use of DCF, the remaining 18 (i.e. 80\%) responded positively to the assessor's use of DCF. But for one participant who responded negatively to the use of DCF, the rest (i.e. 90\%) responded positively that the use of DCF had a positive influence on their post-test scores. The results of the field data show that DCF is effective in treating errors. The findings are in consonance with Ferris (1999), Chandler (2003), Mubarak (2013), Owusu (2017), Owusu (2019), Owusu (2020).

\subsection{The Type of Errors that TU Students Make}

The study revealed that students commit various forms of mechanical, grammatical, and punctuation errors in their texts. With the application of BLAF and DCF technique, these errors were identified and corrected. Examples of mechanical errors found are indicated below:

1. Spelling: expireing (expiring), recieved (received), promt (prompt), fansy (fancy);

2. Spacing: under go (undergo), in deed (indeed), in to (into), infact (in fact);

3. Capitalization: I Wish to... (I wish to...), In may, we... (In May, we...), friday (Friday).

Examples of grammatical errors corrected are listed below:

1. Syntax: I wish to bring to note that... (I wish to bring to your notice that...);

2. Concord: Their names is... (Their names are...), salting help to... (salting helps to...);

3. Tense: The food is process... (The food is processed...), my firm have... (my firm has...);

4. Semantics: All staff should come in full.. (All staff should attend this meeting...);

5. Lexis: Our stuff have... (Our staff have...), we discussed about... (We discussed...).

Examples of punctuation errors spotted and corrected are listed below:

1. Omission: Finally (Finally,) (omitted comma); we voted yes (we voted 'yes') (omitted quotation marks);

2. Incorrect punctuation: The fake one's (The fake ones) (incorrect use of the apostrophe).

\section{Conclusions and Recommendations}

This paper employed Direct Corrective Feedback (DCF) technique in treating the errors found in the scripts of 80 selected participants drawn from Ho, Koforidua, Kumasi, and Sunyani Technical Universities. The paper adopted 
Noticing Hypothesis as the theoretical framework. The findings of the paper revealed that DCF is strong in treating students' errors, as students produced better post-test scripts. Consequently, the following recommendations were given:

1. TU language teachers should use DCF in marking the scripts of students.

2. The continuous assessment of TU students should be made up of both pre and post-test items. This measure may encourage the SLL at the TU level to experience a degree of success in their language assessments, especially in situations where post-test results are recorded.

3. TU teachers should devote at least 10 minutes (of the two credit hours for Communication Skills) for teaching of vocabulary items. This measure can reduce spelling, tense, concord, capitalization, and punctuation errors that TU students make.

4. I propose that TU teachers should use BLAF in assessing letter writing-based tasks.

\section{Limitations and Suggestion for Future Studies}

Every research work has limitations. This current study is no exception. The original plan was to conduct a longitudinal study. However, time factor could not warrant for this kind of study to be conducted, hence the decision to use cross-sectional study. The scope of the human subjects used could also have been widen to include most of the TUs, if not all TUs in Ghana. The number of texts used should have been increased. Also, the interventions used could have been many. Therefore, future research works could explore other interventions like oral corrective feedback (OCF), indirect corrective feedback (ICF), or even no feedback technique. For the human subjects, future research studies may consider participants from some of the other tertiary universities. Since the current study used only pre- and post-test items, future study may consider using mid-test in addition to pre- and post-test items.

\section{References}

Bates, I., Lane, J., \& Lange, E. (1993). Writing clearly: Responding to ESL compositions. Boston: Heinle and Heinle.

Beuningen, C. V. (2010). Corrective feedback in L2 writing: Theoretical perspectives, empirical insights, and future directions. International Journal of English Studies, 10(2), 1-27. https://doi.org/10.6018/ijes/2010/2/119171

Bitchener, J., Young, S., \& Cameron, D. (2005). The effect of different types of corrective feedback on ESL student writing. Journal of Second Language Writing, 14, 191-205. https://doi.org/10.1016/j.jslw.2005.08.001

Chandler, J. (2003). The efficacy of various kinds of error feedback for improvement in the accuracy and fluency of L2 student writing. Journal of Second Language Writing, 12(3), 267-296. https://doi.org/10.1016/S1060-3743(03)00038-9

Chaudron, C. (1988). Second language classrooms: Research on teaching and learning. Cambridge: Cambridge University Press. https://doi.org/10.1017/CBO9781139524469

Creswell, J. W., Plano Clark, V. L., Guttman, M., \& Hanson, W. (2003). Advanced mixed methods research designs. In Tashakkori and C. Teddlie (eds.), Handbook of Methods in Social and Behavioural Research, pp. 209-240. Thousand Oaks, CA: Sage.

Ellis, R. (1998). Teaching and research: Options in grammar teaching. TESOL Quarterly, 32, 39-60. https://doi.org/10.2307/3587901

Ellis, R. (2009). Corrective feedback and teacher development. L2 Journal, 1(1), 3-18. https://doi.org/10.5070/L2.V1I1.9054

Ellis, R., Loewen, S., \& Erlam, R. (2006). Implicit and explicit corrective feedback and the acquisition of L2 grammar. Studies of Second Language Acquisition, 28(2), 339-368. https://doi.org/10.1017/S0272263106060141

Farrokhi, F., \& Sattarpour, S. (2012). The effects of direct written corrective feedback on improvement of grammatical accuracy of high-proficient L2 learners. World Journal of Education, 2(2), 49-57. https://doi.org/10.5430/wje.v2n2p49

Ferris, D. R. (1995c). Teaching ESL composition students to become independent self-editors. TESOL Journal, 4(4), 18-22.

Ferris, D. R. (1999). The case for grammar correction in L2 writing classes: A response to Truscott (1996). 
Journal of Second Language Writing, 8(1), 1-11. https://doi.org/10.1016/S1060-3743(99)80110-6

Ferris, D. R. (2003). Response to student writing: Implications for second language students. Mahwah, NJ: Lawrence Erlbaum Associates. https://doi.org/10.4324/9781410607201

Ferris, D. R., \& Roberts, B. (2001). Error feedback in L2 writing classes: How explicit does it need to be? Journal of Second Language Writing, 10(3), 161-184. https://doi.org/10.1016/S1060-3743(01)00039-X

Han, Z. H. (2008). Error correction: Towards a differential approach. A video on the fourth QCC Colloquium on Second Language Acquisition, New York.

Hendrickson, J. M. (1978). Error correction in foreign language teaching: Recent theory, research, and practice. Modern Language Journal, 62(8), 387-398. https://doi.org/10.2307/326176

Junqueira, L., \& Payant, C. (2015). "I just want to do it right, but it's so hard": A novice teacher's written feedback beliefs and practices. Journal of Second Language Writing, 27, 19-36. https://doi.org/10.1016/j.jslw.2014.11.001

Kepner, C. G. (1991). An experiment in the relationship of types of written feedback to the development of second-language writing skills. Modern Language Journal, 75(3), 305-313. https://doi.org/10.1111/j.15404781.1991.tb05359.x

Krashen, S. D. (1992). Comprehensible input and some competing hypotheses. In R. Chourchene, J. Glidden, and J. St. John (Eds.) Comprehension-Based Language Teaching. Ottawa: University of Ottawa Press. pp. 19-38.

Leki, I. (1990). Coaching from the margins: Issues in written response. In B. Kroll (ed.), Second Language Writing: Research insights for the Classroom, pp. 57-68. Cambridge: Cambridge University Press. https://doi.org/10.1017/CBO9781139524551.008

Lightbown, P. M., \& Spada, N. (1999). How languages are learned. Oxford: Oxford University Press.

McClave, H. (2008). Communication for business, 4th edition. Dublin: Gill and MacMillan Ltd.

Méndez, E. H., Cruz, R. R., \& Loyo, G. M. (2010). Oral corrective feedback by EFL teachers at Universidad de Quintana Roo. International FEL Memo, 1, 240-253. Retrieved from http://fel. uqroo

Mubarak, M. (2013). Corrective feedback in L2 writing: A study of practices and effectiveness in the Bahrain context. Ph.D. thesis, University of Sheffield, UK.

Owusu, E. (2017). Impact Of Corrective Feedback On The Writing Of Business Communication Students In Selected Tertiary Institutions In Ghana. (Unpublished PhD thesis, University of Ghana, Legon, Accra, Ghana)

Owusu, E. (2019). Corrective feedback and its effects on memoranda and letters of students of Sunyani Technical University, Ghana. The International Journal of Humanities and Social Studies, 7(4), 206-219. https://doi.org/10.24940/theijhss/2019/v7/i4/HS1904-059

Owusu, E. (2020b). The effects of corrective feedback on the business communication texts of technical university students. Applied Linguistics Research Journal, 25-39. https://doi.org/10.14744/alrj.2020.46320

Pakbaz, R. (2014). The effect of written corrective feedback on EFL learners' writing performance: Explicit vs. implicit. International Journal of Language and Linguistics, 2(4), 12-17.

Renandya, W. A., \& Widodo, H. P. (ed.) (2016). English language teaching today. Cham: Springer International Publishing. https://doi.org/10.1007/978-3-319-38834-2

Robb, T., Ross, S., \& Shortreed, I. (1986). Salience of feedback on error and its effect on EFL writing quality. TESOL Quarterly, 20, 83-95. https://doi.org/10.2307/3586390

Schmidt, R. (1990). The role of consciousness in second language learning. Applied Linguistics, 11(2), 129-158. https://doi.org/10.1093/applin/I.2.129

Schmidt, R. (1993a). Awareness and second language acquisition. Annual Review of Applied Linguistics 13(March), 206-226. https://doi.org/10.1017/S0267190500002476

Schmidt, R. (1994). Implicit learning and the cognitive unconscious: Of artificial grammars and SLA. In N. Ellis (ed.), Implicit and Explicit Learning of Language. London: Academic Press.

Schmidt, R. (1995b). Consciousness and foreign language learning: A tutorial on the role of attention and awareness in learning. In R. Schmidt (ed.), Attention and Awareness in Foreign Language Learning. 
Honolulu: University of Hawaii.

Schmidt, R. (2001). Attention. In P. Robinson (ed.) Cognition and Second Language Instruction. Cambridge: Cambridge University Press. https://doi.org/10.1017/CBO9781139524780.003

Schmidt, R. (2010). Attention, awareness, and individual differences in language learning. In W. M. Chan, S. Chi, K. N. Cin, J. Istanto, M. Nagami, J. W. Sew, T. Suthiwan, and I. Walker, Proceeding of CLaSIC 2010, Singapore, 2-4, 721-737. Singapore: National University of Singapore.

Semke, H. D. (1984). Effects of the red pen. Foreign Language Annals, 17, 195-202. https://doi.org/10.1111/j.1944-9720.1984.tb01727.x

Sheppard, K. (1992). Two feedback types: Do they make a difference? RELC Journal, 23, 103-110. https://doi.org/10.1177/003368829202300107

Truscott, J. (1996). The case against grammar correction in L2 writing classes. Language Learning, 46(2), 327-369. https://doi.org/10.1111/j.1467-1770.1996.tb01238.x

Truscott, J. (1999). The case for "The case against grammar correction in L2 writing classes": A response to Ferris. Journal of Second Language Writing, 8(2), 111-122. https://doi.org/10.1016/S1060-3743(99)80124-6

Truscott, J. (1998). Noticing in second language acquisition: A critical review. Second Language Research, 12(2), 103-135. https://doi.org/10.1191/026765898674803209

\section{Notes:}

Note 1. Sequential Exploratory Mixed Methods approach (SEMM), involves the process of first, collecting qualitative data to explain a situation, and then soliciting quantitative data with the view of providing explanations to the relationships established in the qualitative data (Creswell et al. 2003, p. 211).

Note 2. Propounded Owusu (2017, p.117), Business Letter Analytical Framework (BLAF) is a framework that can be employed by language teachers in assessing business letters scripts in a systematic manner. Please see Figure 1.

Note 3. This paper is a direct rebuttal to Truscott (1996).

Note 4. The direct written corrective feedback used, took the form of identification of errors in the scripts of the participants and provision of the correct form of the error above the original, the participants made. The indirect corrective feedback on the other hand, took the form of error underlining only.

Note 5. The topic was: You are the manager of ABC Company Limited. Write a letter to the Director of Food and Drugs Authority explaining how foods are processed in your company.

\section{Copyrights}

Copyright for this article is retained by the author(s), with first publication rights granted to the journal.

This is an open-access article distributed under the terms and conditions of the Creative Commons Attribution license (http://creativecommons.org/licenses/by/4.0/). 